\title{
Microstructural Evolution in Austenitic and Martensitic Steels Irradiated to High Damage Levels
}

\author{
L.N. Brewer, P. Lu, P.G. Kotula, and K. Hattar \\ Sandia National Laboratories, P.O. Box 5800-MS 0889 Albuquerque, NM 87185-0889
}

Our country's energy needs are driving a renewed interest in power generation and waste management and reviving fast neutron reactor technology. While promising, fast neutron reactors will drive materials requirements in different directions from the more standard thermal neutron reactors. However, there are presently no operating fast neutron reactors in the United States. Even when fast reactors in the U.S. become operational again, available time for materials experiments on nuclear reactors is limited and may not be sufficient for achieving the high levels of damage, 100-200 displacements per atom (dpa), that are necessary for understanding materials life issues. A means for accelerated testing of irradiation damage in a laboratory environment is clearly necessary.

We are using high energy $(>10 \mathrm{MeV})$, heavy ion irradiation at high temperatures $\left(400-600^{\circ} \mathrm{C}\right)$ to simulate fast neutron damage in austenitic (316L) and ferritic-martensitic (420) steels. This approach has been used in the past on a variety of steels, including 316L, but primarily at lower levels of displacement damage, e.g. 40dpa)[1]. To extend this work to higher damage levels, we have irradiated 316L and 420 steels using a matrix of temperatures, damage levels, and damage rates. These ranges will allow comparison with previous ion studies [1,2], related literature from fast neutron experiments [3], and predictions about what will happen with exposures up to 100dpa. After exposure, TEM sections were made using an FEI DB235 focused ion beam at $30 \mathrm{keV}$ for initial milling and $5 \mathrm{keV}$ for final polishing. Some sections were post processed using the Fischione Nanomill. TEM imaging experiments were performed on a Philips CM30 TEM. STEM-based hyperspectral imaging experiments were performed on an FEI Tecnai F30-ST TEM/STEM with an EDAX energy dispersive x-ray detector. The hyperspectral $\mathrm{X}$-ray imaging data was statistically analyzed using Sandia's Automated eXpert Spectral Image Analysis (AXSIA) software to produce high spectral contrast in the components [4].

Ion irradiation of 316L stainless steel causes both damage structure evolution and radiation induced segregation (RIS). While the dislocation networks are qualitatively similar, the density of defects is approximately an order of magnitude higher for these exposures (100dpa) compared to those observed for previous work (40dpa) [1]. The observed voids in these samples are quite small and vary systematically as a function of depth from the surface (Figure 1). RIS of silicon and nickel (Figure 2) has previously been observed at similar temperature ranges [2]. We will compare these observations with those at higher damage levels (>100dpa) and for a systematic series of damage rates for both $316 \mathrm{~L}$ and 420 steels.

References:

1. Sindelar, R.L. et al., Journal of Nuclear Materials, (1985). 133-134: p. 544-548.

2. Lee, E.H. and E.A. Kenik, Journal of Materials Research, (1988). 3(5): p. 840-844.

3. Kenik, E.A. and K. Hojou, Journal of Nuclear Materials, (1992). 191: p. 1331-1335.

4. Kotula, P.G. and M.R. Keenan, Microscopy and Microanalysis, (2006). 12(6): p. 538-544. 
5. Sandia is a multiprogram laboratory operated by Sandia Corporation, a Lockheed Martin Company, for the United Stated Department of Energy's (DOE) National Nuclear Security Administration (NNSA) under contract DE-AC0494AL85000
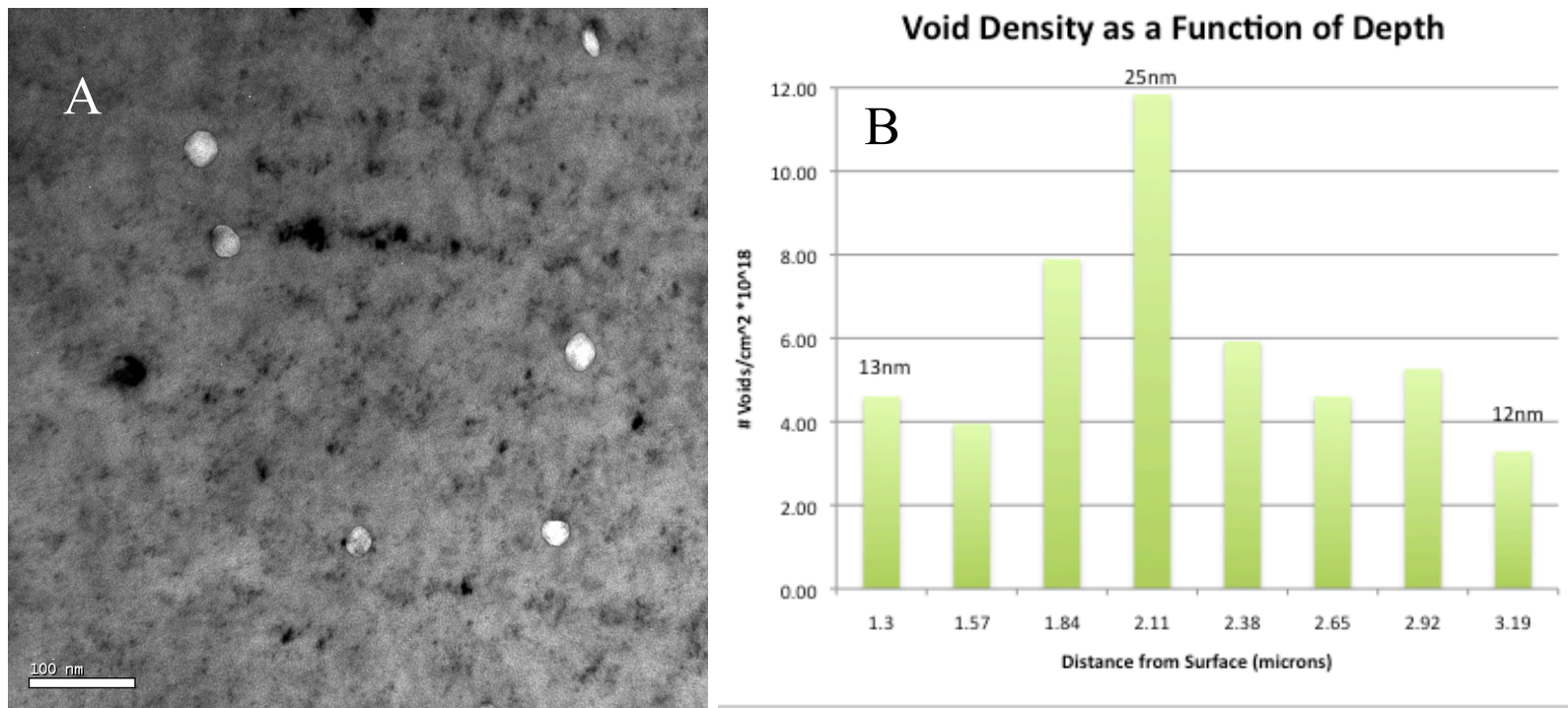

Figure 1. A.) TEM bright field image of voids formed by nickel ion $(20 \mathrm{MeV})$ irradiation at $600^{\circ} \mathrm{C}$ to a damage level of 100dpa. B.) Histogram of void densities as a function of depth from surface. Superscript numbers indicate the average void size at those locations.
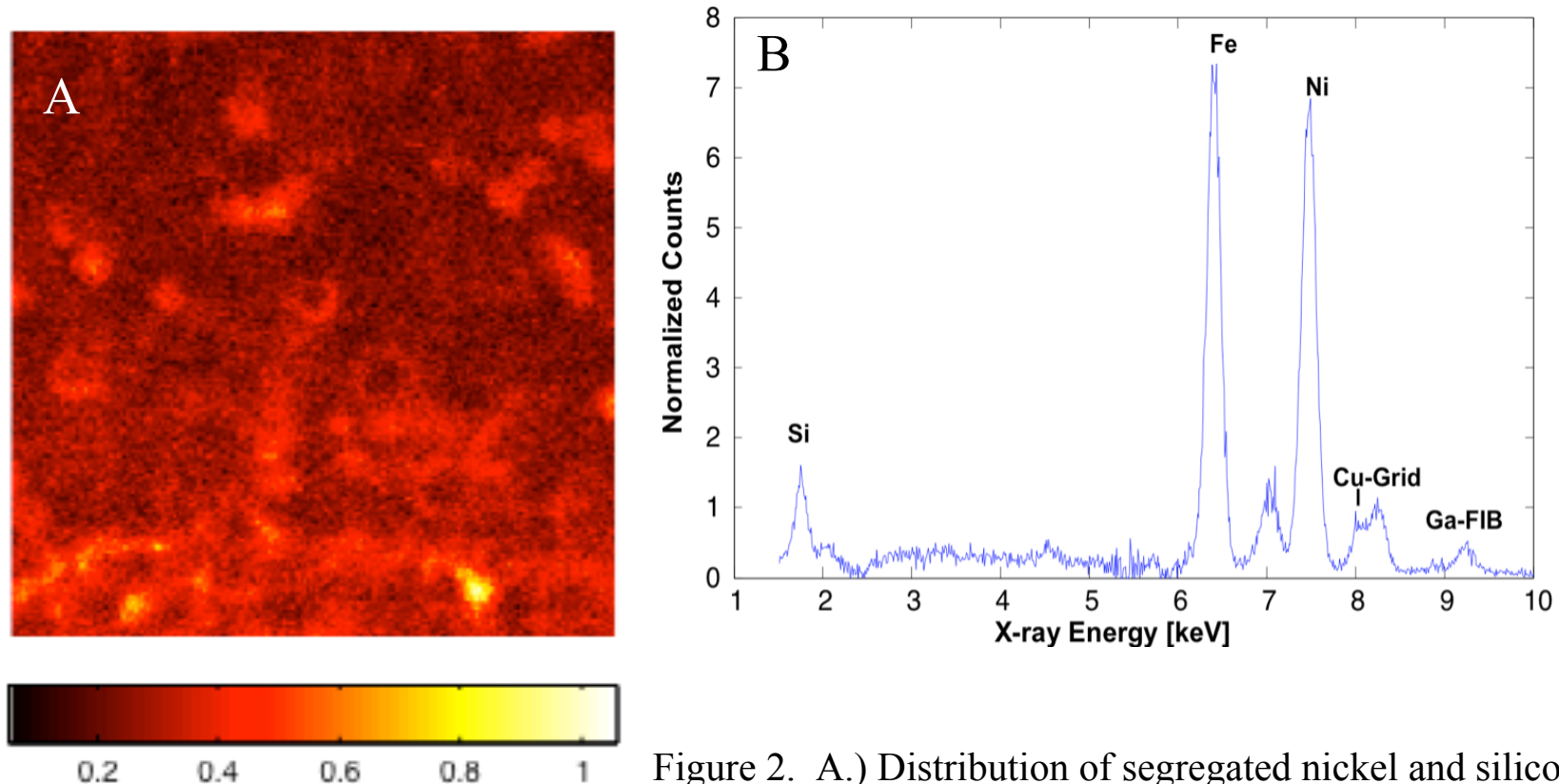

Figure 2. A.) Distribution of segregated nickel and silicon for sample in Figure 1. One side of the image is $500 \mathrm{~nm}$. B.) Corresponding component X-ray spectrum showing enhanced nickel and silicon peaks. 